\title{
Görüntü İşlemede Görüntü Kalitesinin Belirlenmesi için Alternatif Bir İstatistiksel Yaklaşım: Bland-Altman Metodu
}

\author{
Şevkiye BABACAN*1(1) İbrahim KILIÇ2 (i) \\ ${ }^{1}$ Afyon Kocatepe Üniversitesi, Fen Bilimleri Enstitüsü, istatistik Anabilim Dalı, Afyonkarahisar, Türkiye \\ ${ }^{2}$ Afyon Kocatepe Üniversitesi, Veterinerlik Fakültesi, Biyoistatistik Anabilim Dalı, Afyonkarahisar, Türkiye
}

(Alınış / Received: 17.03.2021, Kabul / Accepted: 06.05.2021, Online Yayınlanma / Published Online: 25.12.2021)

\author{
Anahtar Kelimeler \\ İstatistiksel Metot \\ Karşılaştırma, \\ Bland Altman Metodu, \\ Görüntü Kalitesi
}

Özet: $\mathrm{Bu}$ çalışmada en iyi görüntü kalitesinin belirlenmesi amacryla bulanıklaştırılmış görüntüler orijinal görüntü ile karşılaştırılmıştır. Literatürde görüntü kalitesini belirlemede kullanılan bazı klasik yaklaşımlar Normalleştirilmiş Çapraz Korelasyon, Normalleştirilmiş Mutlak Hata, Yapısal İçerik, Tepe Sinyal Gürültü Oranı değerleridir. Bu çalışmada bilimsel araştırmalarda iki metodun karşılaştırılmasında kullanılan Bland-Altman Metodu, ilk kez görüntü kalitesinin belirlenmesi amacı ile kullanılmıştır. İstatistiksel analizler için ilk olarak görüntü standardının sağlanması amacıyla Afyon Kocatepe Üniversitesinin logosu 8 bit derinliğinde 256 x 256 boyutlarında gri tonlamalı bir görüntüye dönüștürülmüștür. Bu görüntü orijinal görüntü olarak ele alınıp A olarak adlandırılmıştır. Karşılaştırılan görüntüler ise orijinal görüntünün gürültü eklenerek bulanıklaştırılmış $B, C$ ve $D$ olarak adlandırılan üç görüntüsünden oluşmaktadır. İlgili görüntüler rassal olarak seçilen ve k, k1 ve k2 olarak adlandırılan 0-256 arasındaki farklı üç satır ve bu satırlara karşı gelen sütunlara ait piksellerin değerlerinden elde edilmiștir. Daha sonra bulanıklaștırılmıș görüntülerin orijinal görüntü ile ikili karşılaştırmaları, Bland-Altman Metodu ile gerçekleştirilmiştir. Yapılan analizler sonucunda B, C ve D olarak adlandırılan bulanık görüntüler arasından orijinale en yakın görüntünün hem klasik yaklaşımlarla hem de öne sürülen Bland-Altman yaklaşımı ile B görüntüsü olduğu belirlenmiştir. Elde edilen sonuçlar ilgili tablo ve şekillerde ayrıntılı olarak verilmiştir.

\section{An Alternative Statistical Approach for Determining Image Quality in Image Processing: Bland-Altman Method}

\section{Keywords}

Statistical Comparison, Bland-Altman Method, Image Quality

\begin{abstract}
In this study, blurred images were compared with the original image in order to determine the best image quality. Some classical approaches used in determining image quality in the literature are Normalized Cross Correlation, Normalized Absolute Error, Structural Content, Peak Signal to Noise Ratio values. In this study, the Bland-Altman Method, which is used to compare two methods in scientific research, was used for the first time to determine image quality. For statistical analysis, the logo of Afyon Kocatepe University was transformed into a grayscale image with $256 \times 256$ dimensions in 8-bit depth in order to provide the image standard first. This image was taken as the original image and named $\mathrm{A}$. The compared images consist of three images called B, C and D of the original image blurred with noise. Relevant images were obtained from the values of pixels belonging to different rows 0-256 and corresponding columns, named k, k1 and $\mathrm{k} 2$, which were selected randomly. As a result of the analysis, it was determined that among the blurred images named B, C and D, the closest image to the original was the B image with both classical approaches and the proposed Bland-Altman approach. The results obtained are given in the relevant tables and figures in detail.
\end{abstract}




\section{Giriş}

Günümüzde dijital teknolojinin gelişmesi ve insanlar tarafından gerçekleștirilen işlemlerin otonom sistemlere yaptırllmak istenmesinden dolayı görüntü işlemenin önemi artmıştır $[1,4]$.

Görüntü işleme, gelişmiş bir görüntü elde etmek veya ondan bazı yararlı bilgiler elde etmek için bir görüntüyü dijital forma dönüștürmek ve üzerinde bazı işlemler gerçekleştirmek için kullanılan bir yöntemdir [2]. Görüntü işleme, bir görüntü veri kaynağı, bir işleme öğesi ve işlenen sonuçlar için bir çıkış biriminden oluşur. Görüntü verilerinin kaynağı bir kamera, bir sensör, uydu, tarayıcl, matematiksel bir denklem, istatistiksel veriler, Web, bir SONAR sistemi vb. olabilir. İşleme elemanı bir bilgisayardır, işlenen sonuç için çıkış noktası ve işlem bir görüntü monitörü olabilir [3]. Görüntü işleme, bir görüntünün görüntü kalitesini artırma, görüntü üzerinde bulunan nesnenin elde edilmesi veya nesnenin tanımlanabilmesi gibi farklı amaçlarla kullanılmaktadır [4]. Dijital görüntü işleme, bozuk bir görüntü analizi için gerekli olan özellikleri zorluk çekmeden belirlenmesine yardımcı olan değiștirilmiş bir görüntünün dönüştürülmesi olarak tanımlanabilir. Herhangi bir görüntünün sayısal temsili olan piksel olarak bilinen 2 boyutlu bir sayı dizisi üzerinde elektronik bir veri işlemedir [5].

Tarihsel süreçte görüntü işleme üzerinde yapılan çalışmalar incelendiğinde; ilk olarak 1920'li yıllarda gazeteler dijital baskılar kullanmaya başlamıș, 1964'te Range 7 uzay aracının çektiği resim iyileştirilmiş, 1979 'ta sağllk alanında dijital görüntü işleme kullanılmaya başlanmış, 1980'lerden sonra ise askeri, endüstri, reklamcllı, coğrafya, istatistik gibi birçok alanda kullanılmaya başlandı görülmektedir [6].

\subsection{Görüntü İşlemede Temel Kavramlar}

Görüntü işleme alanında kullanılan fakat buna rağmen sıklıkla karıștırılan bazı terminolojiler şunlardır;

Dijital görüntü, iki boyutlu (2-D) renk izgarasıyla eşleşen örneklenmiş bir veri kümesidir 2 boyutlu alanda görseller rakamlar kullanılarak temsil edilir. Siyah beyaz bir görüntü için her bir piksel bir sayıdan oluşurken renkli görüntülerde, her bir piksel birden fazla sayıdan oluşur. Siyah beyaz görüntüler 0 ile 255 arasında değer alır ve 0 siyah pikseli temsil ederken 255 beyaz piksel için karşılık gelir [7]. Renkli görüntü pikseli, kırmızı (R), yeşil (G), mavi (B) olmak üzere üç ana renk ile temsil edilir ve genellikle RGB olarak da adlandırılır [7,8]. Bir endüstri terimi olan piksel (Picture element) [9]. Görüntünün en küçük unsurunu ifade eder ve temel bilgi birimi olan sayısal ifadeler içerir [5]. Bir diğer tanım ise görüntünün bir satır ve bir sütun kesişimi olarak da ifade edilir [10].
Çözünürlük, inç ya da $\mathrm{cm}$ başına düşen piksel sayısıdır [11]. Bir görüntünün boyutu çözünürlüğü ile belirlenir. Bir görüntü çözünürlüğü genellikle görüntünün sütun ve satır boyutları tarafindan oluşturulan piksel sayısıdır. (örneğin; 640×480, 800x600,1024x768 vb.) Bit çözünürlüğü, bir pikselin olası renk yoğunluğunun sayısal değerini tanımlar [5]. İkili bir görüntüde sadece siyah-beyaz iki renk mevcutken, gri tonlamalı bir görüntüde siyahtan beyaza değișen 256 faklı gri tonlamaya mevcuttur $[1,5]$. Uzaysal Frekans, iki boyutlu görüntülerin gerçek uzayda var olan yoğunluk veya renk dağılımlarını dikkate alan ve yaygın olarak kullanılan güçlü bir metodolojidir [5].

\subsection{Görüntü İşleme Yöntemleri}

Görüntü işlemede amaç orijinal halinde olmayan görüntüyü görsel olarak güçlendirmek ve istatistiksel olarak değerlendirmektir. Bu amaç görüntü üzerinde etkili olabilecek işlemlerin gerçekleștirilmesi ve uygulanması ile yürütülür. Görüntü işleme üç ana başlıkta incelenebilir. Birincisi optik, ikincisi analog ve üçüncüsü dijital yöntemlerdir [12].

\subsection{Beyaz Gürültü}

Beyaz gürültü herhangi bir spesifik sinyalden ziyade sinyaller ve sinyal kaynakları için istatistiksel bir model anlamına gelir. Beyaz gürültü, istatistiksel sinyal işlemenin geliştirilmesinde ve model oluşturulmasında kritik rol oynar [13]. Beyaz gürültünün örneklerin bağımsız olması ve aynı olasılık dağılımına sahip olması gerekir diğer bir değişle bağımsız ve aynı șekilde dağıtılmış rasgele değișkenler beyaz gürültünün en basit tanımıdır [14]. Beyaz gürültünün özel bir hali olan Gauss beyaz gürültüsünün temeli, ortalaması $(\mu)$ sıfır, varyansı $\sigma^{2}$ olan standart normal dağılıma dayanır.

\subsection{Dürtü Gürültüsü}

Dürtü gürültüsü ya da diğer ismiyle çift üstel dağılımına sahip gürültü [15] genellikle bir aygıtın donanımındaki veya kameranın sensöründeki bir kusur nedeniyle görüntüleri bozar. Dürtü gürültüsü, orijinal görüntüdeki bazı piksellerin yerini alır. Dürtü gürültüsünün iyi bilenen iki türü vardır ki bunlardan birincisi iki değerden (0-55) birini alan tuz ve biber gürültüsü, ikincisi ise (0-255) aralığında herhangi bir değer alabilen rastgele değerli dürtü gürültüsüdür [16].

\section{Materyal ve Metot}

Çalışmada Afyon Kocatepe Üniversitesinin logosu, kullanılmıştır. Görüntünün işlenebilmesi ve karşılaştırmaların bir standartta yapılabilmesi amacı ile 8 bit derinliğinde $256 \times 256^{\prime}$ lık gri tonlamalı logo referans görüntü olarak ele alınmış, karşılaştırılmak amaçlı kullanılacak diğer üç görüntü ise bu 
görüntünün Dürtü gürültüsünde sıklığı (d) 0.05, 0.20 ve 0.40 olacak şekilde bulanıklaştırılarak elde edilmiştir. İstatistiksel analizler MATLAB ve MedCalc programları yardımı ile gerçekleștirilmiştir.

Elde edilen görüntüler arasındaki uyum incelenerek orijinal görüntüye en yakın görüntünün belirlenmesinde literatürde yaygın olarak TSGO, NÇK, NMH, Yİ gibi kriterlerden ve bu çalışma kapsamında alternatif olarak öne sürülen Bland-Altman metodundan yararlanılmıștır. Çalıșmada kullanılan bu kriterler ve metoda ilişkin ayrıntılı açıklamalar aşağıda verilmektedir.

\subsection{Görüntü Kalitesi}

Görüntü kalitesinin belirleyicisi insanlardır. Dahası insanoğlunun görme yetisi doğuştan gelen özel bir yetenektir. Görüntü kalitesinin belirlenmesinde insanoğlunun bu yeteneğinin bilgisayarlar tarafindan yapılarak benzer sonuçların elde edilmesi amaçlanmaktadır. Bir görselin kalitesini belirlemede ortalama görüş puanı dikkate alınabilir.

Görüntü kalitesi belirlenirken birçok kişi tarafından kalitesiz olarak değerlendirilen bir görsel düşük ortalama görüș puanına sahipken, daha iyi bir kaliteye sahip görselin daha yüksek bir ortalama görüş puanına sahiptir. Görüntü kalitesini belirlemede istatistiksel teknikler, objektif görüntü kalite ölçümleri ve metriklerinden yararlanılır $[17,18]$. Görüntü kalite ölçümleri Tablo 1'de, kalite metrikleri ise bölüm 2.1.1 ve 2.1.2'de verilmiștir.

\subsubsection{Tepe Sinyal Gürültü Oranı (TSGO, Peak Signal Noise Ratio PSNR)}

Görüntü üzerinde yapılan bir işlem önemli bilgi ya da kalite kaybına neden olabilir. Görüntü kalitesinin belirlenmesinde kullanılan objektif metriklerden biride tepe sinyal gürültü oranıdır. Orijinal görüntü $f$, test görüntüsü $g$ olmak üzere $M \times N$ boyutlu iki görüntü için TSGO değeri Eşitlik (1)'de verildiği gibi hesaplanır [19].

$$
\operatorname{TSGO}(f, g)=10 \log _{10}\left(\frac{255^{2}}{H K O(f, g)}\right)
$$

Burada HKO değeri Eşitlik (2)'te görüldüğü gibi hesaplanır.

$$
H K O(f, g)=\frac{1}{M N} \sum_{i=1}^{M} \sum_{j=1}^{N}\left(f_{i j}-g_{i j}\right)^{2}
$$

\subsubsection{Normalleştirilmiş Çapraz Korelasyon (NÇK, Normalized Cross Correlation NCC)}

A ve B olarak adlandırılan iki görüntü arasındaki benzerliğin ölçülmesinde kullanılan normalleştirilmiş çapraz korelasyon katsayısı Eşitlik (3)'te ki gibi hesaplanabilir [20].

$$
S_{m_{1} m_{2}}=\frac{\sum_{u=-w}^{w} \sum_{v=-w}^{w}\left[A_{u v}-\bar{A}\right] \cdot\left[B_{u v}-\bar{B}\right]}{(2 w+1)(2 w+1) \sigma(A) \sigma(B)}
$$

Burada $\bar{A}$ ve $\bar{B}$ görüntülere ait ortalamalar ve $\sigma(A)$ ve $\sigma(B)$ ise standart sapmalardır.

$\mathrm{Bu}$ tekniklerin dişında her ne kadar korelasyon katsayısından da görüntü kalitesinin belirlenmesinde yararlanılsa bile istatistiksel açıdan iki görüntü kalitesini belirlemede korelasyonlarına bakmanın doğru bir yaklaşım olmadığı konusunda görüşler de hakimdir. Zira Giavarina (2015) çalışmasında korelasyonun iki değişken arasındaki ilişkinin derecesini belirlemede kullanılabileceğini ancak yüksek bir korelasyon otomatik olarak iki metot arasında yüksek bir uyumun olduğu anlamına gelmediğini vurgulayarak korelasyon katsayısı ve regresyon analizinin gözlemlenen iki veri seti arasındaki doğrusal beraberliğin belirlenmesinde kullanıldığından, uyumun belirlenmesinde uygun teknik olmayacağını ifade etmiştir.

\subsection{Bit derinliği}

Dijital görüntüdeki her bir nokta sayısı ne kadar çok ise gerçeğe o denli benzer bir netliktedir. Görüntüyü oluşturan en küçük yapının (piksel) alacağı renk farklılığının fazla olması gerçeğe daha yakın bir renk olmasına sebep olur. Ayrıca görüntüdeki pikselin renk bilgisini verir.

Bit derinliği aynı zamanda renk derinliği şeklide de ifade edilir. Bunun nedeni bit derinliği yüksek bir görüntünün her bir pikseli daha fazla renk bilgisine sahip olabilir [22].

\section{Örneğin;}

- 1 bit derinliği olan görüntünün piksellerinin iki olası değeri vardır: siyah-beyaz.

- 8 bit derinliği olan görüntünün $2^{8}$ veya 256 olası değeri vardır.

- $\quad$ Bit derinliği 8 olan gri tonlama modundaki görüntülerin 256 olası gri değeri vardır.

Tablo 1. Görüntü kalite ölçümleri

\begin{tabular}{lc}
\hline Normalleştirilmiş Mutlak Hata (NMH, Normalized Absolute Error NAE) & $N M H=\frac{\sum_{j=1}^{M} \sum_{k=1}^{N}\left[O\{F(j, k)\}-O\left\{\widehat{F}(j, k)^{2}\right]\right.}{\sum_{j=1}^{M} \sum_{k=1}^{N}[O\{F(j, k)]}$ \\
\hline Yapısal İçerik (Yİ, Structural Content SC) & $Y \dot{I}=\sum_{j=1}^{M} \sum_{k=1}^{N}[F(j, k)]^{2} / \sum_{j=1}^{M} \sum_{k=1}^{N}[\hat{F}(j, k)]^{2}$ \\
\hline
\end{tabular}


8 bitlik gri bir görüntü için piksel değerleri 0-255 arasında olup Şekil 1'de de görüleceği üzere, beyaz bir nokta için bu değer 255, siyah bir nokta için ise 0 olacaktır.

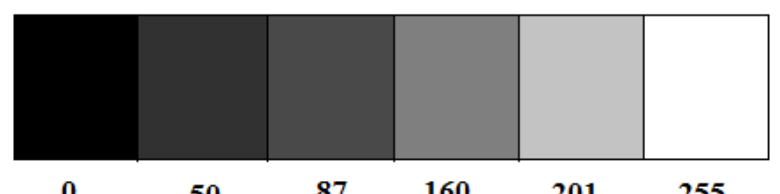

Şekil 1.8 bit derinliğinde siyah-beyaz ve gri tonlamalı renk skalası.

\subsection{Entropi Yaklaşımı}

Shannon iletişimin temel problemi olarak gördüğü, bir noktada seçilmiş bir mesajın yaklaşık olarak ya da tamamen başka bir noktada yeniden üretilme sürecinde bilgi kaybını azaltabilmek için araştırmalar yapmıştır. Geliştirdiği formül için de iki tabanlı logaritmayı kullanmıştır. Yapılan işlemlerde, logaritmanın alınması, entropiyi bağımsız sistemler için toplanabilir bir nitelik haline getirmektedir. Çalışmalarında, logaritmanın kullanışlı olduğunu belirterek sayısal kodlama sistemine uygun olduğu için iki tabanlı logaritmayı seçmiştir. Bu şekilde entropi sisteminde çıkan sonuç, 'bit' olarak adlandırılmıştır. İkili kodlama sisteminde iki sabit durum, sıfır ve bir olmaktadır [23]. h bilgi içeriği, p olayın gerçekleşme olasılığı olmak üzere, Eşitlik (4) yardımıyla hesaplanır.

$$
h=\log \frac{1}{p} \text { ve ya } h=-\log p
$$

Bir sistemin mümkün tüm durumları ve bunların olasılıkları belirlendiğinde, sisteme ilişkin ortalama veya beklenen bilgi içeriği de hesaplanabilir. Örneğin bir sistemin mümkün durumları $\mathrm{X}$ tesadüfi değişkeni ile tanımlanırsa, beklenen bilgi içeriği Eşitlik (5) ile hesaplanabilir.

$$
H(x)=-\sum p \log p
$$

\subsection{Bland Altman Metodu}

Aynı değişkenin Klinik ölçümüne sahip iki metot arasındaki uyum, ölçüm değerleri arasındaki farklar kullanılarak ifade edilebilir. Ortalama farklar $(\bar{d})$ ölçümün şiddetinden kaynaklı olarak orantılı da olabilir. Bu etkiler ortalama grafiğe karşı çizilen farklar grafiği yardımı ile de kolaylıkla görülebilir [24].

Yöntem karşılaştırması çalışmasına iki yöntemden elde edilen ölçümlerin ortalamalarına karşı farklarının saçılım grafiğinin çizilmesi ile başlanır. Farklara karşı ortalamaların grafiği ölçüm hataları ile gerçek değerler (gerçek değerler elde edilemediğinden onun en iyi kestiricisi olan ortalamalar) arasında olabilecek herhangi bir ilişkinin incelenmesine olanak sağlar. Ayrıca bu grafikten yan'ın ve hatanın incelenmesi de mümkündür [25]. Farklar ve ortalamalar arasında ilişki yoksa iki yöntem arasındaki uyum farkların ortalaması $(\bar{d})$ ve standart sapması (s) kullanılarak incelenebilir [26]. Eğer farklar normal dağılıma sahipse farkların sıfırın etrafında rasgele dağılması ve \%95'inin " $\bar{d}-1,96 \mathrm{~s}$ ile $\bar{d}+1,96 s$ " arasinda olması beklenir. $\mathrm{Bu}$ durum altında ortalamalar ve farklar arasında ilişki olmadığı söylenebilir. $\mathrm{Bu}$ yöntemde, $d \pm 1,96 s$ "uyum sinırları" olarak adlandırılır $[25,27,28]$.

\section{Uygulama}

Çalışmanın uygulama kısmında Afyon Kocatepe Üniversitesinin logosu orijinal görüntü olarak ele alınmıştır. Bu görüntü ile beraber farklı özelliklerde bulanıklaştırılmış üç görüntü analizlere dahil edilmiştir. Bu görüntüler Tablo 1'in içerisinde sırası ile A, B, C ve D simgeleri ile gösterilmiştir. Görüntülerin karşılaştırılmasında MedCalc ve MATLAB paket programından yararlanılmış ve her bir görüntü program içerisinde işlenerek matris formatına çevrilmiştir.

Tablo 2 incelendiğinde her bir görüntünün entropi değerleri ve entropi değerlerinin orijinal görüntü entropisine oranlanması ile elde edilen Göreli Etkinlik (GE) değerleri de görülmektedir. Entropisi ve göreli etkinliği yüksek olan görüntülerin orijinal ve orijinale en yakın görüntüler olduğu görülmektedir.

Tablo 2. Analiz edilen görüntüler ile bunlara ilişkin Entropi ve Göreli Etkinlik değerleri

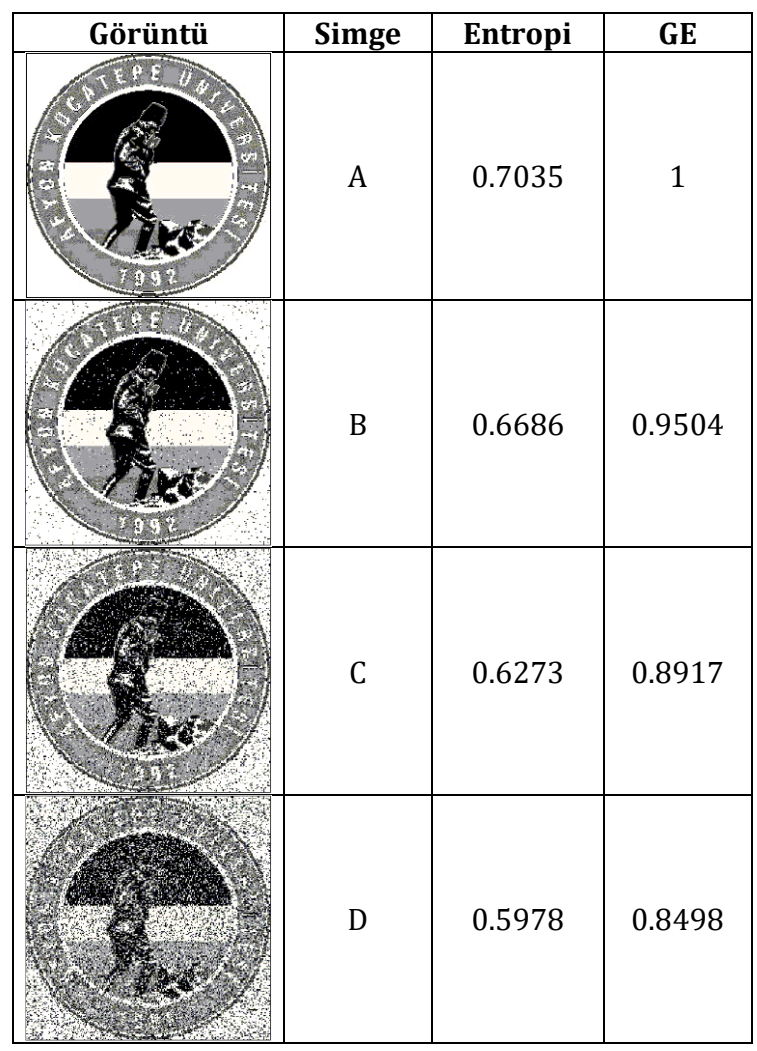


Ele alınan $\mathrm{B}, \mathrm{C}$ ve $\mathrm{D}$ görüntülerinden hangisinin orijinal görüntüye en yakın olduğunu belirlemede ilk olarak literatürde mevcut olan ve sıkça kullanılmakta olan Tepe Sinyal Gürültü Oranı (TSGO), Normalleştirilmiş Çapraz Korelasyon (NÇK), Normalleştirilmiş Mutlak Hata (NMH), Yapısal İçerik (YI) değerlerine bakılmıştır. Tablo 3'de verilen bu değerler incelendiğinde ikili karşılaştırmalar sonucunda A-B karşılaştırmasından elde edilen değerlerin görüntü benzerliği konusunda diğer görüntü karşılaştırmalarına nazaran daha iyi sonuçlar verdiğinden, orijinale en yakın görüntünün B görüntüsü olduğu görülmektedir.

Tablo 3. Ele alınan görüntülerin orijinal ile ikili karşılaştırılmalarına ilişkin değerler

\begin{tabular}{lllll}
\hline $\begin{array}{l}\text { Karşılaștırılan } \\
\text { Görüntü }\end{array}$ & NÇK & NMH & TSGO & Yi \\
\hline A-B & 0.8810 & 0.2618 & 9.5044 & 1.0557 \\
A-C & 0.8148 & 0.3198 & 8.4702 & 1.1567 \\
A-D & 0.7102 & 0.4473 & 6.7683 & 1.3021 \\
\hline
\end{tabular}

Çalışmada alternatif bir yaklaşım olarak öne sürülen teknik için üç farklı k değeri k, k1 ve k2 olacak şekilde rassal olarak seçilerek bu ele alınan görüntüde bu $\mathrm{k}$ değerlerine ait satıra karşı gelen sütunlar için piksel değerlerinin oluşturduğu dağılımlar dikkate alınmıştır. Çalışmada k, k1 ve k2 değerleri rassal olarak sırası ile 82, 93 ve 168 olarak belirlenmiștir. Şekil 2, Şekil 3 ve Şekil 4'te A, B, C ve D görüntülerinin bu $\mathrm{k}$ değerlerine karşı gelen sütunlarındaki sayısallaştırılmış piksel değerlerinin dağılım grafikleri görülmektedir.

Çalışmada daha sonra k, k1 ve k2 değerlerine karşı gelen sütunlardaki piksel değerlerinin oluşturduğu dağılıma ait değerler MedCalc programına girilerek, Bland-Altman analizi gerçekleştirilmiştir. Orijinal ile mevcut görüntülere ait $\mathrm{k}$ değeri için ortalama farkların ikili karşılaştırmalarına ait Bland-Altman grafikleri Şekil 5. a, b ve c'de, k1 değeri için ilgili Bland-Altman grafikleri Şekil 6. a, b ve c'de ve k2 değeri için ilgili Bland-Altman grafikleri Şekil 7. a, b ve c'de verilmektedir.

Şekil 5a, 6a ve 7a'da k, k1 ve k2 değeri için orijinal görüntü (A) ile bulanıklaştırılmış görüntü (B) için Bland-Altman analizi sonuçları görülmektedir. A ve B görüntülerine ilişkin elde edilen değerlerin farklarına ait bu üç grafik incelendiğinde, A-B gözlemlerine dayalı ortalama farkların genel olarak güven sınırları içerisinde kaldığı (b) ve (c) grafiklerine nazaran güven aralığının daha dar olduğu dolayısı ile A görüntüsüne en yakın görüntünün $B$ görüntüsü olduğu söylenebilir.

Benzer olarak Șekil 5b, 6b ve 7b'de k, k1 ve k2 değeri için orijinal görüntü (A) ile bulanıklaştırılmış görüntü (C) için ve Şekil 5c, 6c ve 7c'de ise yine k, k1 ve k2 değeri için orijinal görüntü (A) ile bulanıklaştırılmış görüntü (D) için Bland-Altman analizi incelendiğinde gerek güven sınırları içerisinde kalan ortalama farklar gerekse (d) değerleri ve buna bağlı güven aralıklarına bağlı olarak $\mathrm{B}$ görüntüsünden sonra orijinal görüntü olan A'ya en çok benzeyen görüntülerin $C$ ve $D$ görüntüleri olduğu söylenebilir.

Bland-Altman analizi sonucunda elde edilen bu bulgular, klasik tekniklerden elde edilen bulgularla benzer sonuçlar sergilediği gibi, çalışmanın başında dürtü gürültüsü eklenen bulanıklık miktarları da dikkate alındığında, en az bulanıklaştırılan (d değeri en düşük) görüntünün en benzer görüntü olarak analiz sonuçlarında kendisini göstermesi de çalışma bulguları açısından önemli bir sonuçtur.

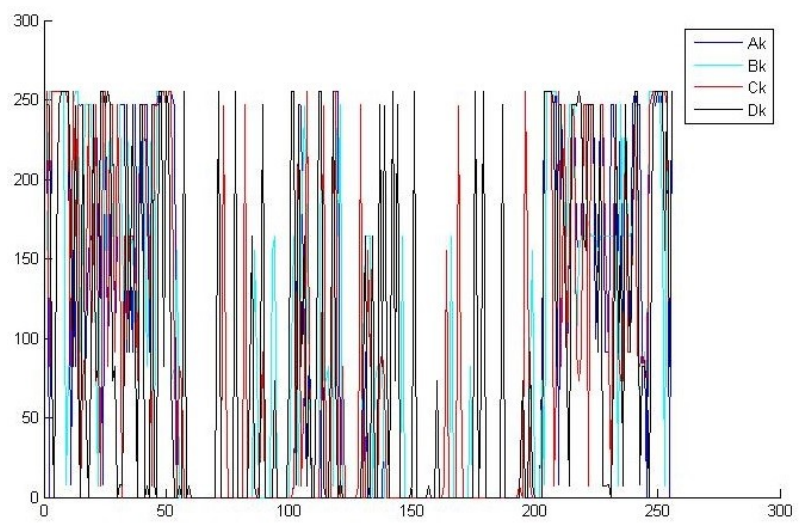

Şekil 2. Ak, Bk, Ck ve Dk görüntülerinin k=82 satırına karșı gelen sütunlarındaki piksel değerlerinin grafiği.

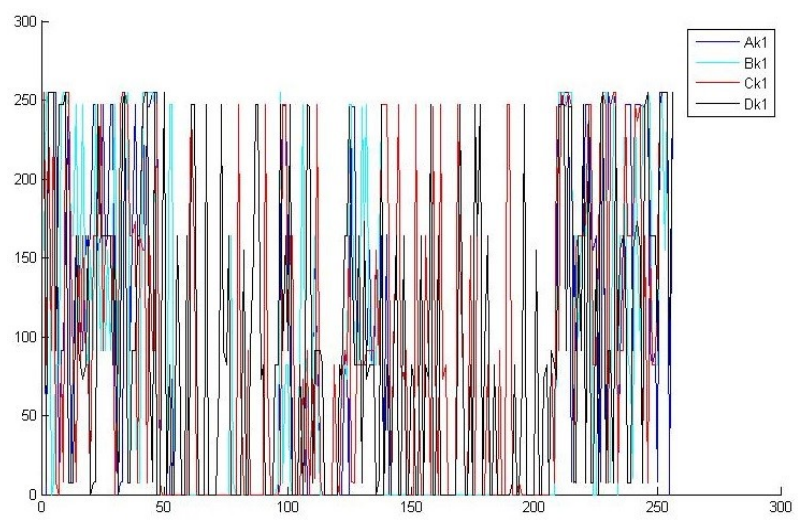

Şekil 3. Ak1, Bk1, Ck1 ve Dk1 görüntülerinin k1=93 satırına karșı gelen sütunlarındaki piksel değerlerinin grafiği.

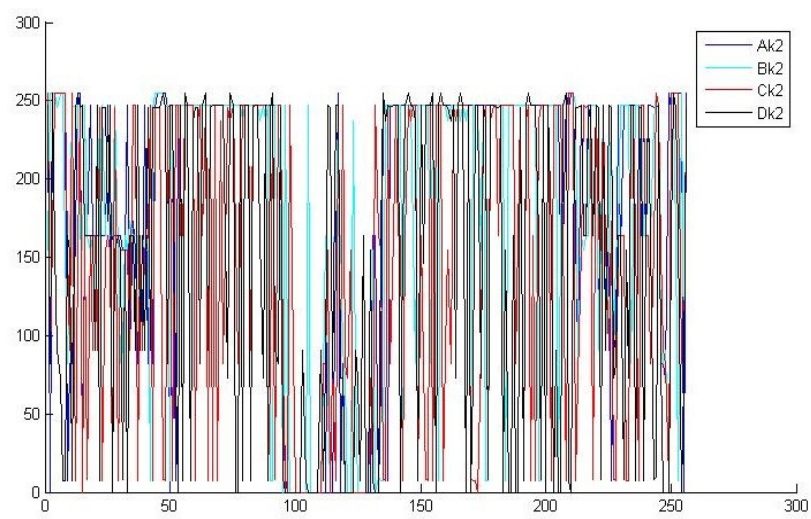

Şekil 4. Ak2, Bk2, Ck2 ve Dk2 görüntülerinin k2=168 satırına karşı gelen sütunlarındaki piksel değerlerinin grafiği. 


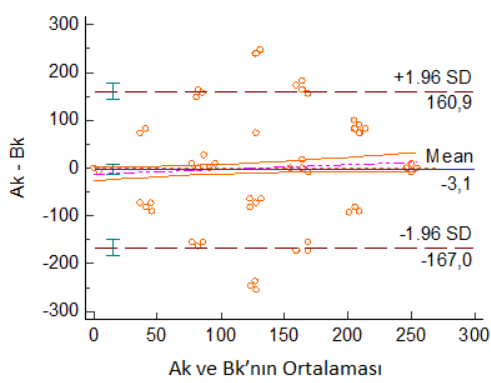

(a)

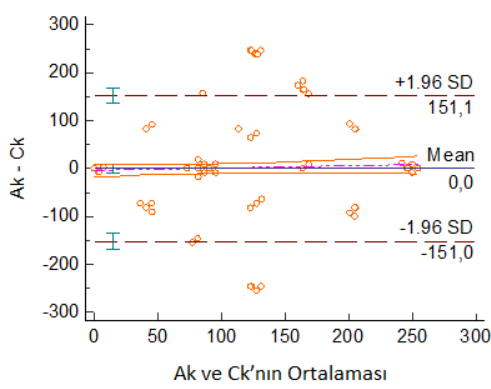

(b)

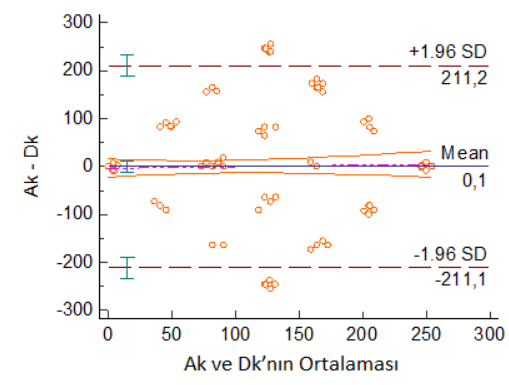

(c)

Şekil 5. Bland-Altman analizi sonucunda k değeri için ikili karşılaştırma sonuçlarına ait grafikler.

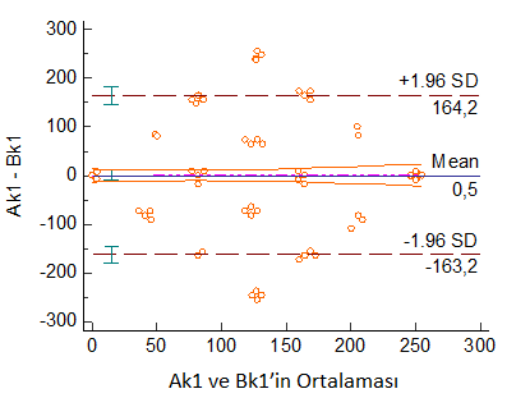

(a)

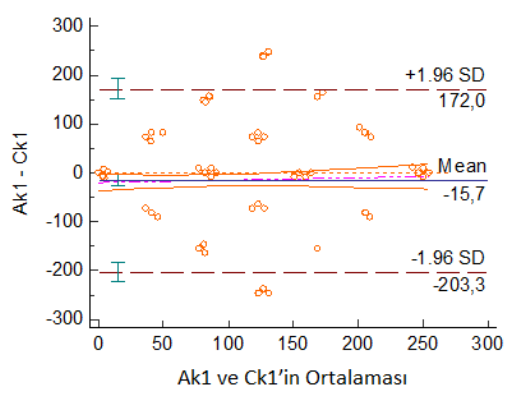

(b)

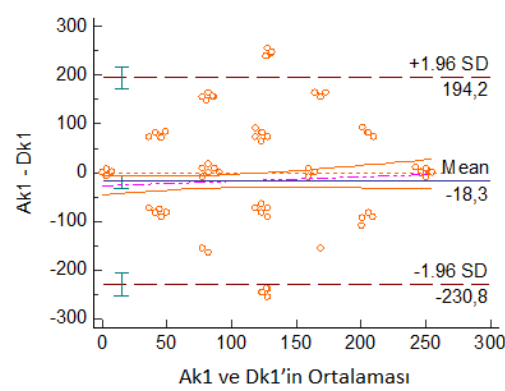

(c)

Şekil 6. Bland-Altman analizi sonucunda k1 değeri için ikili karşılaştırma sonuçlarına ait grafikler.

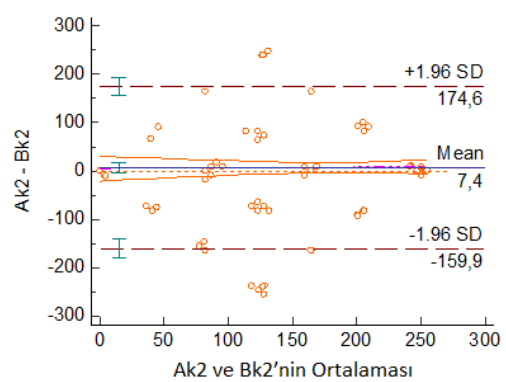

(a)

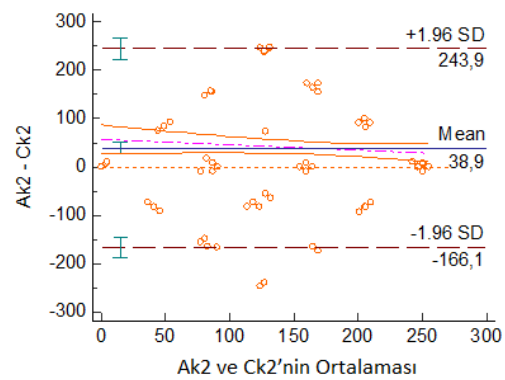

(b)

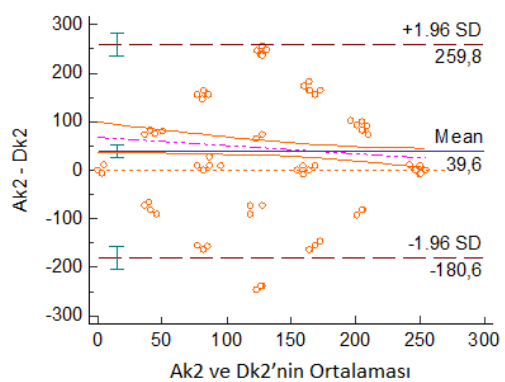

(c)

Şekil 7. Bland-Altman analizi sonucunda k2 değeri için ikili karşılaştırma sonuçlarına ait grafikler.

\section{Tartışma ve Sonuç}

Son yıllarda teknolojideki hızlı gelişmeler, veriye verilen önemin ve sağlıklı veri analizinin öneminin artmasına bağlı olarak istatistik bilimine verilen önemin de arttığını görmek, istatistikçiler için sevindirici bir durumdur. Ancak istatistik bilgisi yeterli olmayı teknolojiyi iyi kullanabilen araştırmacıların elde ettikleri bilgi kalitesinin arttırılmasında alanında iyi bir istatistikçinin varlığı büyük önem arz etmektedir. Görüntü işleme ve görüntü kalitesinin belirlenmesi amaciyla her ne kadar farklı birçok istatistiksel teknik ve yaklaşımdan yararlanılsa da farklı bakış açılarına bağlı olarak yeni yaklaşımların geliştirilmesi daha kolay uygulanabilir, maliyeti daha az, sağlıklı tahmin ve sonuçların elde edilmesine sebep olacaktır. $\mathrm{Bu}$ noktada farklı yaklaşımların geliştirilmesi konusunda istatistikçilere de büyük görevler düşmektedir. Görüntü kalitesinin belirlenmesinde yaygın olarak TSGO, NÇK, NMH, Yİ gibi kriterler dikkate alınmaktadır. Bu çalışmada da görüntüler arasındaki uyum incelenerek orijinal görüntüye en yakın görüntünün belirlenmesi amaçlanarak bu kriterlere alternatif bir yaklaşım sunulmaya çalışılmıştır.

Farklı ölçümlerden elde edilen gözlem değerlerine ilişkin ikili karşılaştırmalar İstatistiksel olarak uyuma ve ilişkiye yönelik karşılaştırmalar olarak ayrılabilir. İki farklı ölçüm arasındaki ilişkinin yüksek olması ikisinin birbirine çok benzer olduğu anlamına gelmeyeceği gibi, birbirine çok benzeyen ölçümler arasındaki ilişkinin de her zaman yüksek çıkmasını beklemek doğru olmayacaktır. Zira ele alınan değişkenler arasındaki ilişki araştırılırken kullanılan birçok ilişki katsayısı bile ilişkinin doğrusal olduğu varsayımına dayanarak hesaplamaları gerçekleştirmekte doğrusal olmayan ilişkiler söz 
konusu olduğunda yanlış çıkarımlara sebep olmaktadır.

Önerilen Bland-Altman metodu, mevcut iki ölçüm arasındaki uyumu karşılaştırmak amaçlı daha çok klinik araştırmalarda kullanılan istatistiksel bir yaklaşımdır. Bu metot ayrıca ele alınan ölçümlerin ortalama farklarının grafiğini çıkararak görsel karar vermeye yardımc bir metottur. $\mathrm{Bu}$ metodun karşılaştırma yaparken iki teknikten birisini referans olarak ele alması bu çalışmada karşılaștırılan görüntülerin referans bir görüntüyle karşılaştırılması açısından da benzerlik göstermektedir.

Analiz sonuçları Bland-Altman yöntemi sonucunda elde edilen bulguların klasik yöntemlerle örtüştüğünü, dolayısıyla bu yöntemin de orijinal görüntü ile karşılaştırma yaparak görüntü kalitesini belirlemede kullanılabilecek alternatif bir yöntem olduğunu göstermektedir.

Yapılan bu çalışmanın literatüre en büyük iki katkısından birisi, karşılaştırılacak görüntülerin rassal olarak seçilen bir satırındaki piksellere ait sayısal değerleri alması (işlem hacmi ve zaman tasarrufu olarak değerlendirilebilir) diğeri ise daha önceden kullanılmamış olan Bland-Altman Metodu ile mevcut görüntüler arasındaki uyuma karar vermesidir. $\mathrm{Bu}$ bağlamda çalışmanın gelecekte yapılacak çalışmalara katkı sağlaması ümit edilmektedir.

\section{Teşekkür}

Bu çalışmada başta Doç. Dr. Sinan Saraçlı olmak üzere danışmanım İbrahim Kılıç'a teşekkür ederim. Bu çalışma Şevkiye Babacan'ın Afyon Kocatepe Üniversitesi Fen Bilimleri Enstitüsü İstatistik ABD'de devam etmekte olan İbrahim Kılıç danışmanlığındaki YL tezinden üretilmiştir.

\section{Etik Beyanı}

$\mathrm{Bu}$ çalışmada, "Yükseköğretim Kurumları Bilimsel Araştırma ve Yayın Etiği Yönergesi" kapsamında uyulması gerekli tüm kurallara uyulduğunu, bahsi geçen yönergenin "Bilimsel Araştırma ve Yayın Etiğine Aykırı Eylemler" başlığı altında belirtilen eylemlerden hiçbirinin gerçekleştirilmediğini taahhüt ederiz.

\section{Kaynakça}

[1] Yıldız, N. 2010. Görüntü İşlemenin Dünü, Bugünü ve Geleceği, Elektrik Mühendisliği Dergisi, 440(1), 11-16.

[2] Marry, R. 2011. Introduction to Image Processing. https://webier.link/0ihqv (Erişim Tarihi:28.02.2021).

[3] Shoyab, M., Begum, S., Shawal, S., 2014. Fundamentals of Digital Image Processing and
Basic Concept of Classification. International Journal of Chemical and Process Engineering Research, 1(6): 98-108.

[4] Eldem, A., Eldem, H., Palal A. 2017. Görüntü İşleme Teknikleriyle Yüz Algllama Sistemi Geliştirme, BEÜ Fen Bilimleri Dergisi 6(2), 4448.

[5] Solomon, C., Breckon, T. 2011, Fundamentals of digital image processing: A practical approach with examples in Matlab. WileyBlackwell. 355s.

[6] Çayıroğlu, İ. Görüntü İşleme ve Temel Kavramlar. https://webier.link/pjwp3 (ErişimTarihi:28.02.2021).

[7] Kuo, M. S., Lee, H. B., Tian, W. 2006. Introduction to Digital Image Processing, Real-Time Digital Signal Processing, 579-626.

[8] Suentens, P. 2017. Introduction to Digital Image Processing, Fundamentals of Medical Imaging, 1-14.

[9] Jackson, W. 2015. Digital Image Compositing Fundamentals. Apress, 171s.

[10] Young, I. T., Gebrands. J. J., Vliet. L. J. 1995. Fundamentals of Image Processing. Copyright, 113s.

[11] Kesimal B. 2017. Görüntü İșeme. https://webier.link/it5hg (Erişim Tarihi:04.03.2021).

[12] Aytan, A. E., Öztürk Y., Örgev, E. K. 1993. Görüntü İşleme, İ.Ü. Diş Hekimliği Dergisi, 27(4), 273-277.

[13] Balakrishkan, A. V., Mazumdar, R. R. 2010. On Powers of Gaussian White Noise, 57(11), 110.

[14] Stein, M. L. 1999. Interpolation of Spatial Data: Some Theory for Kriging. Springer Series in Statistics. Springer. 40s.

[15] Laligant, O., Truchetet, F., Fauvet, E. 2013. Noise estimation from digital step-model signal, IEEE Trans. Image Processing, Dec., 22(12), 5158-67.

[16] Awad A., 2019. Denoising images corrupted with impulse, Gaussian, or a mixture of impulse and Gaussian noise, Engineering Science and Technology, an International Journal, 22(3), 746-753,

[17] Dosselmann, R., Yang, D. X. 2005. Existing and Emerging Image Quality Metrics, Saskatoon, 1906-1913.

[18] Egizarian, K., Astola, J., Ponomarenko, N., Lukin, V., Battisti, F., Carli M. 2006. A New Full-Reference Qualıty Metrıcs Based On Hvs, Scottsdale, 4 s. 
[19] Horé, A., Ziou, D., (2010). Image quality metrics: PSNR vs. SSIM. International Conference on Pattern Recognition, 10514651, DOI 10.1109/ICPR.2010.579.

[20] Zhao, F., Huang, O., Gao, W. (2006) Image Matching by Normalized Cross-Correlation , Conference Paper in Acoustics, Speech, and Signal Processing Fransa, 14-19 Mayıs 2006;Cilt2,DOI:10.1109/ICASSP.2006.16604 46.

[21] Giavarina, D. 2015. Understanding Bland Altman analysis, Biochemia Medica, 25(2):141-51.

[22] Duyar, U. 2010. Dijital Görüntü Teknolojileri, Elektrik Mühendisliği Dergisi, 440, 17-22.

[23] Ocakçı M., Bostancl S.H. 2009. Kent Siluetlerine İlişsin Tasarım Niteliklerinin Entropi Yaklașımı ile Değerlendirilmesi, İTÜ dergisi/a, 2: 27-36.
[24] Bland, J.M., Altman, D.G. 1999. Measuring agreement in method comparison studies, Statistical Methods in Medical Research, 8: 135-160.

[25] Hollis, S. 1996. Analysis of method comparison studies, Ann Clin Biochem, 33:14.

[26] Bland, J.M., Altman, D.G. 1986. Statistical methods for assessing agreement between two methods of clinical measurement, Lancet; I: 307-10.

[27] Saraçlı, S., Çelik, H.E. 2012. Metot Karşılaştırma Çalışmalarında Bland-Altman ve Tip II Regresyon Analizinin Karşılaştırılması, Düzce Üniversitesi Sağlık Bilimleri Enstitüsü Dergisi, 2(1): 11-14.

[28] Genç, Y., Sertkaya, D., Demirtaş, S., 2003. Klinik Araștırmalarda İki Ölçüm Tekniğinin Uyumunu İncelemede Kullanılan İstatistiksel Yöntemler, Ankara Üniversitesi Tıp Fakültesi Mecmuası 56(1):1-6. 